\title{
Adenoid Cystic Carcinoma: An Unusual Neurosurgical Entity
}

\author{
Eugen J. Dolan, Michael L. Schwartz, Anthony J. Lewis, Edward E. Kassel and Perry W. Cooper
}

\begin{abstract}
Adenoid cystic carcinoma, or cylindroma, usually presents in the salivary glands or in the upper respiratory passages. We report an unusual case of adenoid cystic carcinoma in a 45-year-old woman who presented with a three-year history of progressive right trigeminal sensory palsy, most pronounced in the second division. There was, in addition, a right trigeminal motor palsy and a partial right 6th nerve palsy. CT scanning showed only a small soft tissue mass spanning an enlarged right foramen ovale. Solid adenoid cystic carcinoma was resected from Meckel's cave via a middle cranial fossa approach. A subsequent biopsy of the right maxillary antral mucosa found tumor tissue. We concluded that the tumor originated in the maxillary antrum and spread posteriorly along the infraorbital nerve to enlarge in the foramen ovale. Radiation to a total of $5,000 \mathrm{cGy}$ was given. At 22 months there was neither radiographic nor clinical evidence of recurrence. At 30 months, the development of unsteady gait signalled the presence of recurrent tumor extending backwards from Meckel's cave into the right cerebello-pontine angle.
\end{abstract}

RÉSUMÉ: Le carcinome adénoïde kystique: Une entité neurochirugicale inhabituelle Le carcinome adénoïde kystique, ou cylindrome, se manifeste habituellement dans les glandes salivaires ou dans les voies respiratoires supérieurs. Nous rapportons un cas inhabituel de carcinome adénoïde kystique chez une femme de 45 ans qui avait une histoire de 3 ans paralysie sensorielle progressive du nerf trigeminal droit, plutôt sévère dans la deuxième ramification. Il y avait également une paralysie motrice du nerf trigeminal droit et une paralysie partielle du sixième nerf droit. La tomodensitométrie montra seulement une petite masse de tissu mou traversant un agrandissement du trou ovale droit. Un carcinome adénoïde kystique solide fut résequé de la cave de Meckel par accès a la moyenne fosse crânienne. On a trouvé tissu tumeural dans une autre biopsie de la membrane muquese maxillaire antrale. Nous sommes arrivés a la conclusion que la tumeur est provenu dans l'antre maxillaire et s'entendre postérieurement avec le nerf infraorbital pour s'agrandir dans le trou ovale. La patiente a reçu une dose totale de 5,000 cGy de radiation. À 22 mois il y avait aucune évidence radiographic ni clinical de récurrence. À 30 mois, le développement d'une marche moins stable a signalé la présence d'une tumeur récurrente dépassant postérieurement de la cave de Meckel jusqu'à l'angle pontocérébelleux.

Can. J. Neurol. Sci. 1985; 12:65-68

Adenoid cystic carcinoma, or cylindroma, has been known as a distinct entity for over a century since first described by Billroth (1859). These tumors are better known to our otolaryngological colleagues as they usually present in the major or minor salivary glands, or in the upper respiratory passages. We report a case of adenoid cystic carcinoma in a 45 -year-old woman, which presented initially as a trigeminal neuropathy, and in which the CT scan was useful in localizing the lesion, and suggesting the probable origin and mode of spread of the tumor.

\section{Case Report}

Three years prior to the current admission, this 45 -year-old woman received a right maxillary injection for dental anesthesia. Subsequent to this, she noticed a progressive sensory change in the territory of the right trigeminal nerve. The numbness was most noticeable on the cheek in the second division territory. Three months prior to admission she had formication at the hairline and numbness in the right half of the tongue and inside of the cheek. There was no pain. She also noticed wasting of the right masseter and temporalis muscles.

At admission a partial right trigeminal sensory loss to light touch and pin prick was confirmed. The right corneal reflex was absent. The sensory loss was most marked over the second division territory. There was a partial right sixth nerve palsy and diplopia on right lateral gaze. The remainder of the neurological examination and the general physical examination were normal.

\section{Radiology}

No abnormality of the petrous-temporal bone was noted on plain radiographs. Despite the normal appearance of the floor of the middle cranial fossa on plain film study (including basal view) high resolution axial CT demonstrated an enlarged right foramen ovale (Figure 1). Coronal CT scanning with intravenous enhancement (Figure 2) demonstrated a small mass adjacent to and extending through the foramen ovale, involving both the middle cranial fossa and infratemporal fossa.

\section{Operative findings}

Via a limited temporal craniotomy an extradural approach to Meckel's cave was undertaken (Frazier, 1927). Upon cutting through the dura

From the Division of Neurosurgery, Departments of Surgery, Pathology and Radiology, Sunnybrook Medical Centre and University of Toronto.

Received October 10, 1984. Accepted December 12, 1984.

Reprint requests to: Dr. M. Schwartz, Sunnybrook Medical Centre, University of Toronto, Division of Neurosurgery, 2075 Bayview Avenue, Toronto, Ontario, Canada M4N 3M5 


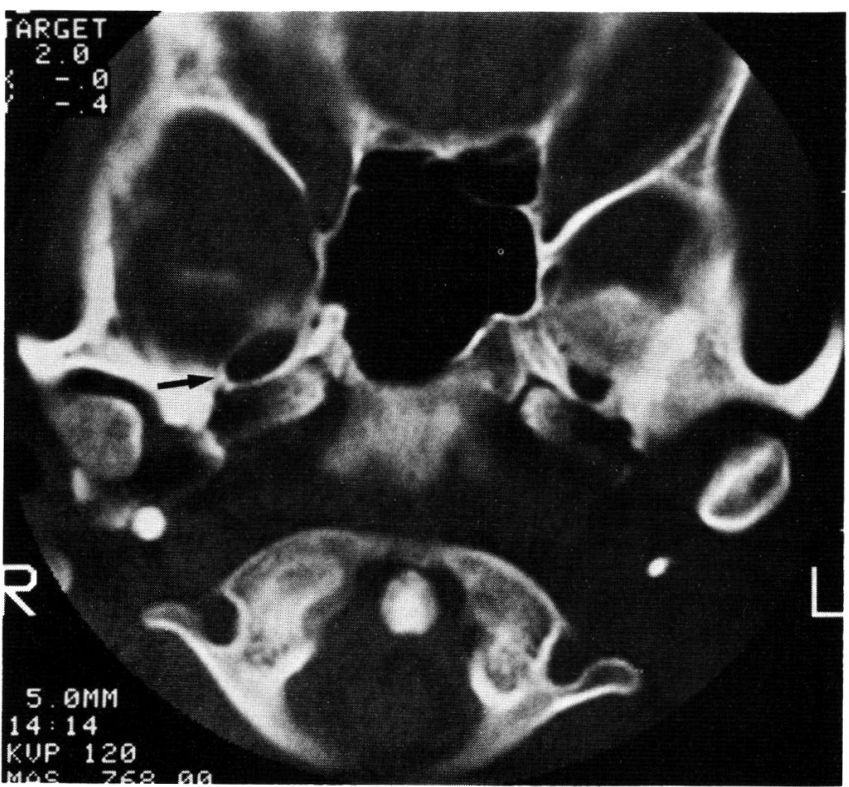

Figure 1 - High resolution axial CT of the skull base demonstrates significant enlargement of the right foramen ovale (arrow).

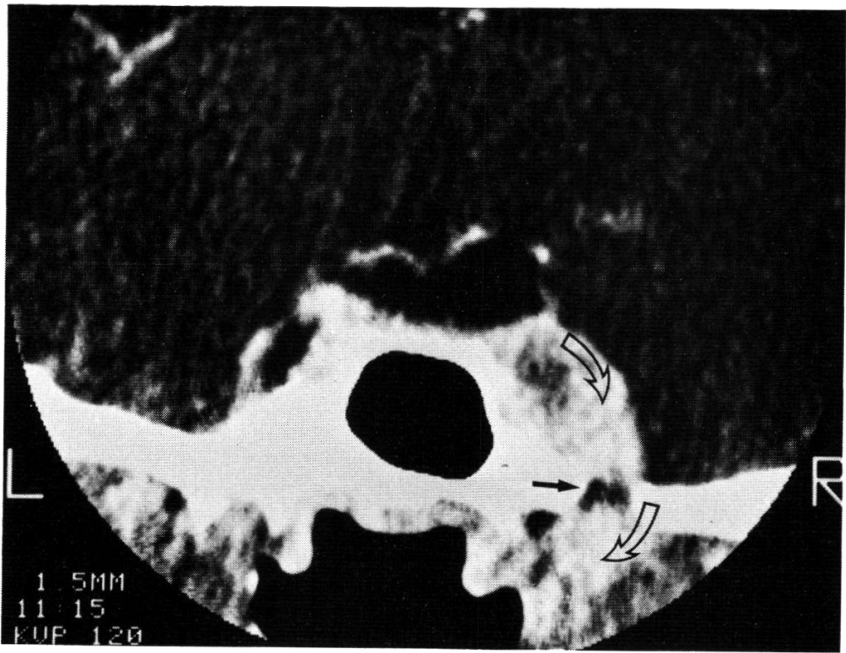

Figure 2 - Coronal CT utilizing intravenous enhancement demonstrates enhancing mass (open arrows) superior and inferior to foramen ovale (solid arrow).

over the mass we encountered soft, pale yellow tumor tissue, and could initially identify neither nerve roots nor the trigeminal ganglion. There was almost no bleeding from the tumor and, after teasing out some of the tumor tissue, we could see that the ganglion was replaced by tumor. Rootlets could be seen entering the tumor mass and sensory fibres could be seen leaving it. The motor division of the mandibular nerve was never identified. Only a partial excision was achieved. The dura was left open and the temporalis muscle and fascia, and skin, were all reapproximated in a single layer due to the extreme atrophy of the temporalis muscle.

\section{Postoperative course}

The patient recovered uneventfully from the operation, but was left with complete trigeminal nerve and abducens palsies. A subsequent examination of the nasopharynx was carried out under anaesthesia with intranasal antrostomy and biopsies of the nasopharynx, Rosenmueller's fossa, the soft palate and the antral mucosa. Tumor tissue was found in the antral mucosa despite the normal appearance of the

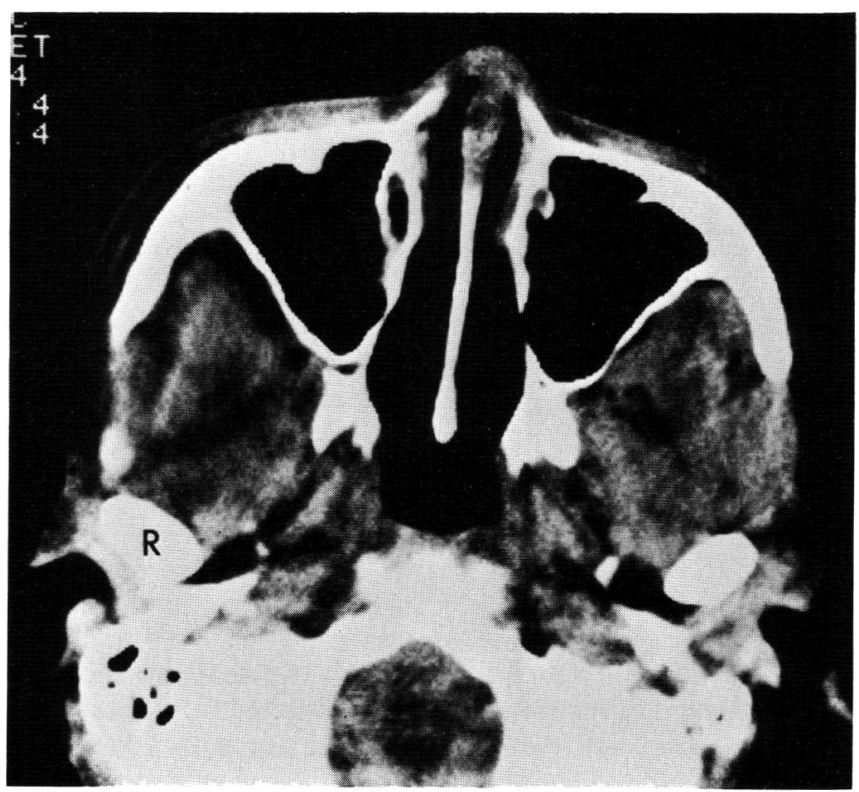

Figure 3-Axial CT through level of maxillary sinus shows no significant abnormality or mass despite positive surgical biopsy of posterior wall right maxillary sinus. Mild atrophy of right temporalis muscle was better noted on other slices as was atrophy of the right masseter and pterygoid musculature.

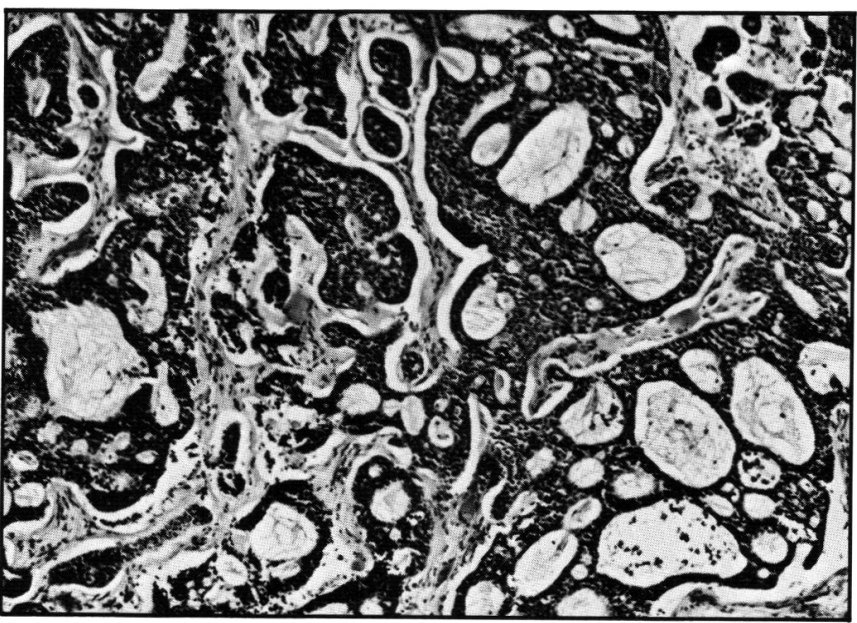

Figure 4-Photomicrograph showing typical adenoid carcinoma from the trigeminal ganglion. $H$ and $E \times 300$.

paranasal sinus on CT scanning (Figure 3). The patient was then treated with irradiation to a total of $5000 \mathrm{cGy}$ in a field that included the right antrum, pterygoid fossa, orbit, ethmoid and nasal cavity.

Over the next six months she recovered partial sensation in all the divisions of the trigeminal nerve with greatest recovery in the first division and the least recovery in the second. There was no improvement in the motor root nor in the sixth nerve function. A CT scan produced at that time showed no evidence of tumor recurrence. The previous abnormal enhancement adjacent to the right cavernous sinus was no longer present.

At 22 months there was a flicker of temporalis and masseter muscle contraction. The remainder of the clinical examination was unchanged. Further CT assessment showed no evidence of recurrence.

\section{Pathological findings}

Pathological examination showed replacement and infiltration of the trigeminal ganglion by a small-cell cribriform carcinoma (Figure 4) with 


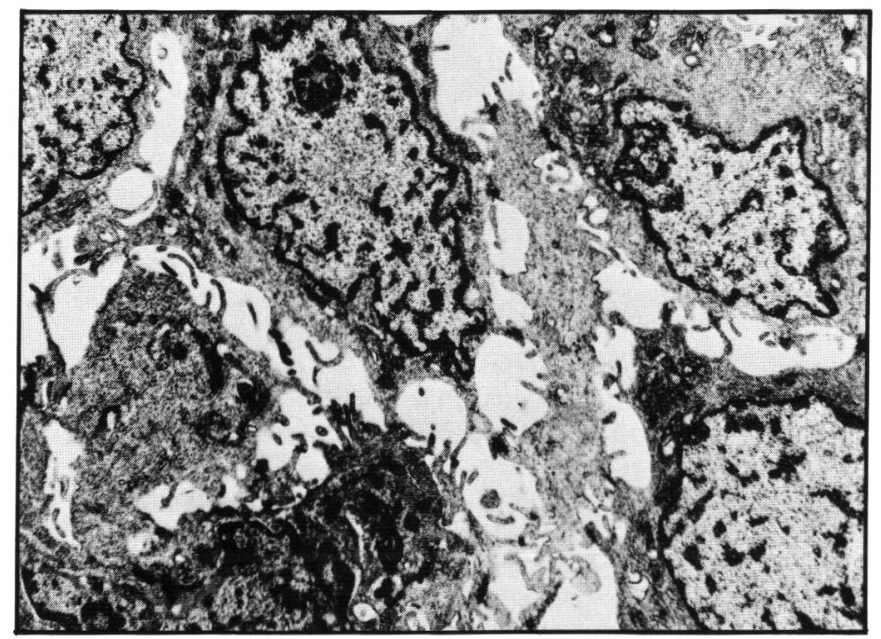

Figure 5-Electronmicrograph showing typical ductal cells with intercellular microvilli and tight junctions. $x$ 14,000.

mucopolysaccharide accumulation in many of the cystic spaces. Tumor nuclei were hyperchromatic, but there was little pleomorphism and scanty mitotic activity. There was extensive stroma which contained normal looking ganglion cells and axons. Electron microscopy (Figure 5 ) showed most of the cells to be ductal, with small intracellular spaces containing microvilli and associated with tight junctions. The cystic spaces were lined by myoepithelial cells with basement-membrane, and contained small stellate granules and a few collagen fibres. Occasional acinar cells with secretory granules and extensive rough endoplasmic reticulum were present. The structure of the lesion was characteristic of adenoid cystic carcinoma (Chen, 1976; Chisholm, 1975; Damjanov, 1979; Evans and Cruickshank, 1970; Thackray and Lucas, 1974). Tumor similar to that in the trigeminal ganglion was found in biopsy from the maxillary sinus mucosa (Figure 6).

\section{DISCUSSION}

Approximately $10 \%$ of all salivary gland tumors (benign and malignant) occur in the minor salivary glands, and of these minor gland tumors $16-25 \%$ are adenoid cystic carcinomas (Batsakis, 1974; Evans and Cruickshank, 1970). Minor gland tumors in general are most frequent in the palate, upper cheek and upper lip, but adenoid cystic carcinoma is disproportionately frequent amongst the less common tumors of the nasopharynx or accessory sinuses. In a series of 61 adenocarcinomas of the nasopharynx or sinuses Batsakis (1974) reported 33 were adenoid cystic carcinoma: In the maxillary antrum 18 of 28 adenocarcinomas were of the adenoid cystic variety. On the other hand, the ethmoidal and frontal sinuses were rarely involved by adenoid cystic carcinoma. While salivary gland tumors in general have a very wide age range, adenoid cystic tumors usually present in the third to fifth decades. There is no sex predominance in Caucasian populations (Evans and Cruickshank, 1970). However, a remarkable feature of the cases of adenoid cystic carcinoma with intracranial extension is the female preponderance $(20 / 24$ cases of known sex), quite different from the sexual equality seen at all other sites. The tumor grows insidiously by local infiltration, particularly in perineural lymphatics and bone (Berdal et al., 1970; Eby et al., 1972). It may spread widely along nerves with pain as a frequent early symptom. In bone it may infiltrate the Haversian canals with relatively little destruction in the early stages, so that it has often spread further than is apparent from radiological examination (Thackray, 1974). Regional lymph

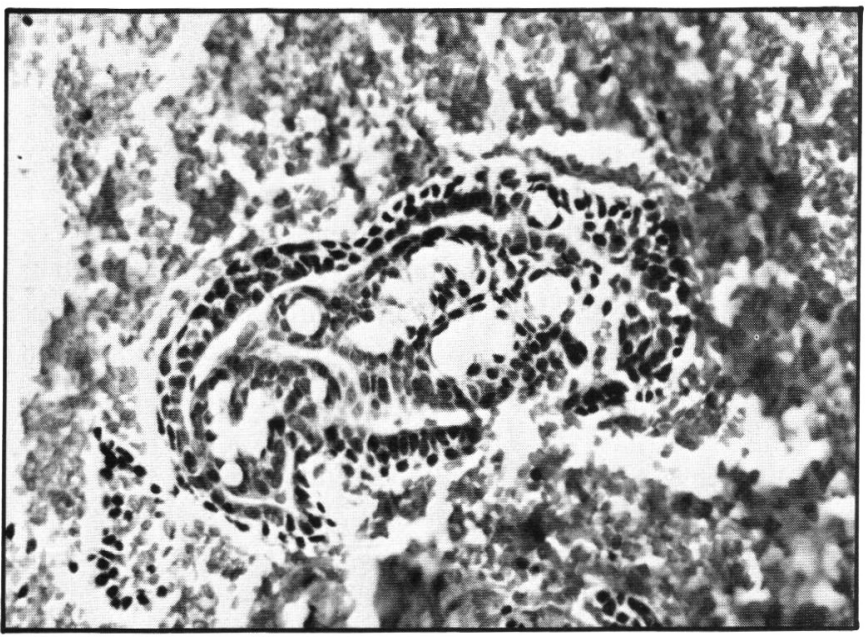

Figure 6 - Photomicrograph showing small fragment of tumour, similar to that from the trigeminal ganglion, found in curettings from the maxillary antrum. $H$ and $E \times 750$

nodes are involved late in the course of spread, and metastases are reported to bone, lung, brain and other organs in up to 20 . $30 \%$ of cases (Batsakis, 1974; Conley et al., 1974; Spiro et al., 1974). After a relentless course, death is often due to infection (including meningitis and brain abscess) or hemorrhage.

It is predictable from the foregoing that adenoid cystic carcinoma may reach the cranial cavity either by direct infiltration in bone or nerve, or by blood-borne metastases (Eby et al., 1972; Eneroth et al., 1966; Spies, 1930). While most authors state that metastases occur there are few estimates of the frequency; figures for metastases to the brain range from 5 to 10 percent (Eneroth, 1966; Seaver, 1979). The combined frequency of metastasis and direct infiltration into brain has been estimated as 22 percent (Conley, 1974). Direct infiltration must often be inferred from the appearance of the tumor at the base of the skull, characteristically in the region of the trigeminal ganglion, often presenting as tic douloureux (Berdal et al., 1974) or in the region of the optic chiasm. At least 26 such cases have been reported (de Benedittis et al., 1977; Bingas, 1974; Fortuna et al., 1971; Gonzalez et al., 1964; Sekino et al., 1969; Yoshimura et al., 1978) and of these, 21 were in the region of the trigeminal ganglion and five in the vicinity of the optic chiasm.

In all previous cases in which the radiologic findings have been noted, erosion of the petrous apex was evident (Bingas, 1974; Dodd, 1972; Fortuna et al., 1971; Gonzalez et al., 1964). The present case of a 45-year-old woman presenting with trigeminal ganglion symptomatology is unusual, in that plain radiographs showed no changes and in particular no petrous apex erosion. CT scanning showed the lesion to be spanning the foramen ovale, enlarging the foramen ovale, and involving both the gasserian ganglion and the infratemporal fossa. Although the exact site of origin of adenoid cystic carcinomas which invade the gasserian ganglion is largely unknown, one may speculate that in the present case it arose in the maxillary antrum. The earliest symptom of numbness most noticeable in the cheek suggests perineural retrograde spread via the infraorbital nerve, and subsequent masseter wasting implies involvement of the motor root. Enlargement of the foramen ovale would then be a sign of subsequent antegrade spread out through foramen ovale along the third trigeminal division. 
Treatment for these patients today is still based on palliation. Radical surgery is still the best chance for cure, with radiation producing tumor regression and pain relief, but not cure (Smith et al., 1965). Chemotherapy has not been shown to provide any significant benefit (Rentschler et al., 1977). All current authors would classify adenoid cystic tumors involving the maxillary antrum as Stage III (American Joint Committee, 1977; Levitt et al., 1981; Spiro et al., 1979). Prognosis in these cases is poor (Grahne et al., 1977; Spiro et al., 1979; Tauxe et al., 1962) and has been shown to relate to the adequacy of surgical resection while histologic grading has not proven useful. Most patients die within five years, so that despite an apparent cure at 22 months the prognosis for this patient remains guarded.

In conclusion, we present a middle-aged female patient with adenoid cystic carcinoma spreading to the gasserian ganglion. CT delineated the lesion spanning the foramen ovale suggesting origin in the posterior maxillary antrum. The $\mathrm{CT}$ was invaluable in defining the lesion and suggesting a probable origin for this patient's tumor.

\section{Addendum}

At 30 months after the partial excision and radiation of the carcinoma, the patient returned with an unsteady gait. There was slight acceleration of the left myotatic reflexes but no cerebellar hemisphere deficit or new cranial nerve palsy. CT scanning demonstrated a polycystic recurrence in the right cerebellopontine angle with displacement of the midbrain back toward the left. A transtemporal approach allowed a subtotal excision of the tumor with improvement in her gait. This time, the tumor consisted of many loculi filled with mucinous material but the appearance of the tumor cells was similar to those of the first surgical biopsy.

\section{REFERENCES}

American Joint Committee for cancer staging and end-result reporting. (1977) Manual for staging of cancer. Chicago.

Batsakis JG (1974) Tumours of the head and neck. Williams and Wilkins, Baltimore. pp 38-51.

de Benedittis G, Bernascore V, Ettorre G (1977) Tumours of the fifth cranial nerve. Acta Neurochirurgica 38: 37-64.

Berdal P, de Besche A, Bylius E (1970) Cylindrome of the salivary glands. Acta Otolaryng 263: 170-173.
Billroth T(1859) Beobachtungen überGeschwülste der Spercheldrusen, Virchow's Arch. Path. Anat. 17: 357-375.

Bingas B (1974) Tumors of the base of the skull. In: Handbook of Clinical Neurology, (ed.) Vinken PI, Bruyn GW, American Elsevier Publishing Co., New York. Vol. 17. pp 186-190.

Chen SY (1976) Adenoid cystic carcinoma of a minor salivary gland. Oral Pathology 42: 606-619.

Chisholm DM (1975) A qualitative and quantitative study of the structure of the adenoid cystic carcinoma of human minor salivary glands. J. Oral. Path. 4: 103-119.

Conley J, Dingman DL (1974) Adenoid cystic carcinoma in the head and neck (cylindrome). Arch Otolaryngol 100: 81-90.

Damjanov I (1979) Ultrastructural pathology of tumours. Eden Press, Montreal. Vol. I. pp 39-40.

Dodd GD, Jing BS (1972) Radiographic findings in adenoid cystic carcinoma of the head and neck. Annals Otol. 81: 591-598.

Eby LS, Johnson DS, Baker HW (1972) Adenoid cystic carcinoma of the head and neck. Cancer 29: 1160-1168.

Eneroth CM, Hjertman L (1966) Adenoid cystic carcinoma of the submandibular gland. Laryngoscope 76: 1639-1661.

Evans RW, Cruickshank AH (1970) Epithelial tumours of the salivary glands. Saunders, Philadelphia. pp 142-166.

Fortuna A, Gambacorta D (1971) Cylindroma in the region of the Gasserian ganglion. J. Neurosurg. 34: 427-431.

Frazier CH (1927) Trigeminal neuralgia. JAMA 89: 1742-1744.

Gonzalez G, Zulch KJ (1964) Über die Zylindromatosen Epitheliome der Schädelbasis, (Zylindrome). Zbl Neurochir 25: 111-125.

Grahne B, Lauren C, Holsti LR (1977) Clinical and histological malignancy of adenoid cystic carcinoma. J. Laryng. Otol. 91(9): 743-749.

Levitt JE, McHugh RB, Gomez-Martin O, et al. (1981) Clinical staging system for carcinoma of the salivary glands. Cancer 47: 2712-2724.

Rentschler R, Burgess MA, Byers R (1977) Chemotherapy of malignant major salivary gland neoplasms. Cancer 40: 619-624.

Seaver PR, Kuehn PG (1979) Adenoid cystic carcinoma of the salivary glands. Amer. J. Surg. 137: 449-455.

Sekino H et al. (1969) Intracranial adenoid cystic carcinoma - report of two cases. Brain and Nerve 21: 709.

Smith LC, Lane N, Rankow RM (1965) Cylindrome (adenoid cystic carcinoma). Amer. J. Surg. 110: 519-526.

Spies JW (1930) Adenoid cystic carcinoma: Generalised metastases in three cases of basal cell type. Arch. Surg. (Chic) 21: 365-404.

Spiro RH, Huvos AG, Strong EW (1974) Adenoid cystic carcinoma of salivary origin. Amer. J. Surg. 128: 512-520.

Spiro RH, Huvos AG, Strong EW (1979) Adenoid cystic carcinoma: Factors influencing survival. Amer. J. Surg. 138: 579-583.

Tauxe WN, McDonald JR, Devine KD (1962) A century of cylindromas. Arch. Otolaryngol 75: 364-376.

Thackray AC, Lucas RB (1974) Tumors of the major salivary glands. Atlas of tumor pathology, 2nd series, Armed Forces Institute of Pathology, Fascicle 10, Washington. pp 91-99.

Yoshimura Y, Hasegawa K, Wada T, Fujita K, Kawakatsu K (1978) Metastasis of adenoid cystic carcinoma of the mandible to the Gasserian ganglion. J. Amer. Dental Assoc. 96: 469-473. 